\title{
Energy Drinks Do Not Improve Le Parkour Performance: A Randomized Controlled Study
}

\author{
Diana Madureira1, Jeferson Oliveira Santana1, Bruno Avelar1, \\ Cesar Augustus de Sousa Zocoler ${ }^{1}$, Bruno Rodrigues ${ }^{1}$, Érico Chagas Caperuto ${ }^{1,2}$ \\ ${ }^{1}$ São Judas Tadeu University, São Paulo, Brazil \\ ${ }^{2}$ Mackenzie Presbiterian University, Barueri, Brazil \\ Email: dianamsantos8@hotmail.com, jsantana_lions@hotmail.com, brunoavelar88@gmail.com, \\ ft.cesar.zocoler@gmail.com, prof.brodrigues@gmail.com, ericocaperuto@gmail.com
}

Received 16 March 2016; accepted 25 April 2016; published 28 April 2016

Copyright (C) 2016 by authors and Scientific Research Publishing Inc.

This work is licensed under the Creative Commons Attribution International License (CC BY). http://creativecommons.org/licenses/by/4.0/

(c) (i) Open Access

\begin{abstract}
Le Parkour is a sport where the athletes transpose common day-to-day obstacles in the best possible way. This sport demands elements like strength, focus and decision making; elements supposedly affected by energy drinks, with performance improvement. The aim of this study was to investigate the effects of energy drink ingestion on Le Parkour athlete's performance. Twelve male amateur athletes, mean age of $23.5 \pm 2.74$, took part in this randomized, double-blind, placebocontrolled study. Subjects were randomly assigned to drink: $250 \mathrm{ml}$ of energy drink, $500 \mathrm{ml}$ of energy drink or placebo. Forty minutes after the beverage consumption, they were evaluated in a specific circuit performance test (time to complete the circuit) followed by a perceived exertion and a circuit technical difficulty evaluation. We also evaluated heart rate in 3 different moments: rest, pre-circuit and post-circuit. All variables were collected in 3 different experimental days. Time, perceived exertion and technical difficulty were higher in the first day compared to the others. Heart rate did not show a difference when we compared the days. Drinking one or two cans of an energy drink did not improve performance of Le Parkour athletes in a sport specific test. It also did not change heart rate or perceived exertion.
\end{abstract}

\section{Keywords}

Caffeine, Double Blind Balanced Design, Sports Performance, Stimulant Drinks

\section{Introduction}

Created in the 80's by David Belle, Le Parkour is known as the art of moving, because its objective is to transpose

How to cite this paper: Madureira, D., Santana, J.O., Avelar, B., de Sousa Zocoler, C.A., Rodrigues, B. and Caperuto, É.C. (2016) Energy Drinks Do Not Improve Le Parkour Performance: A Randomized Controlled Study. Food and Nutrition Sciences, 7, 338-343. http://dx.doi.org/10.4236/fns.2016.74035 
urban space obstacles through basic motor skills (such as walking, running, jumping, climbing and keeping balance) in the most efficient way [1].

Nowadays, it is growing in popularity and number of practitioners [2] and, as in every modality, there is a demand for performance improvement. In that way, a drink that could improve performance in an acute way, such as energy drinks propose to becomes a very attractive resource.

In a general way, energy drinks supposedly promote improvements in alertness, focus, time to reaction, fatigue delay, and well being to its consumers [3]-[5]. These effects are extremely compatible to those required by Le Parkour practice which would make this a great association. In order to do that, they have several substances in their composition, with the most common being caffeine, taurine, carbohydrates, and B complex vitamins [3]-[6]. The substances of the energy drink used in our study and their concentration can be seen in Table 1 .

B complex vitamins as an ingredient of energy drinks are justified due to their antioxidant properties and influence on the energy metabolism [7] [8].

Although taurine effects are not fully understood in scientific literature, its addition to the drinks can be explained due to its properties such as improving glucose tolerance and uptake, and therefore glycogen synthesis [9], aiding contractile function and increasing muscular strength [10] [11].

Carbohydrates represent the largest relative quantity found in the drink. They are the most important energy substrate during high intensity exercise and can prevent hepatic and muscular glycogen reduction [7] [8].

Caffeine is considered the main active ingredient of energy drinks. It acts in the central nervous system through the following actions: release of catecholamines, improving humor, reaction time, and alert state [3] [12]. Caffeine also impacts lipid metabolism resulting in a larger use of lipids as an energy source during exercise, sparing glycogen, delaying fatigue [7], and extending muscle contraction through calcium availability [13].

Currently there is no agreement in the literature as to the energy drink's effects because there are several different drink compositions, amounts ingested, and sport modalities used in the studies that approach this beverage [4] [6].

Therefore, the objective of the present study is to identify the effects of energy drink ingestion on Le Parkour performance.

\section{Material and Methods}

All experimental procedures were approved by the ethical committee for human studies of São Judas Tadeu University by the protocol number CAAE: 13979213.3.0000.0089.

\subsection{Sample}

Subjects were randomly chosen of a Le Parkour group of practitioners and the study was conducted in a counterbalanced and double blind manner. We evaluated 12 male subjects between 20 and 30 years old, mean age of $23.5 \pm 2.74$. Weight mean was $72 \pm 7.56$ and high mean was $1.75 \pm 0.03$.

As inclusion criteria, subjects had to be practicing Le Parkour for at least 6 months and at least 1 to 2 times a week, had to be physically active, and also had to be in excellent health. We excluded subjects that were new to the practice and consumed more then 3 cups of coffee (espresso) a day.

Table 1. Substances and amounts of the energy drink used in the present study.

\begin{tabular}{ccc}
\hline Substances & Amount \\
\hline Caffeine & $80 \mathrm{mg}$ \\
Taurine & $1000 \mathrm{mg}$ \\
Glucuronolactone & $60 \mathrm{mg}$ \\
Carbohydrates & $28 \mathrm{~g}$ \\
Inositol & & $50 \mathrm{mg}$ \\
& & $16 \mathrm{mg}$ \\
Vitamins & B3 & $5 \mathrm{mg}$ \\
& B5 & $1.3 \mathrm{mg}$ \\
& B6 & $1 \mu \mathrm{g}$ \\
\hline
\end{tabular}


Subjects were instructed not to ingest caffeine of any type or any natural source for at least 48 hours before the test, as well as they had to abstain from exercise for this time. After the explanation of all procedures, all subjects signed the Informed Consent Form.

\subsection{Study Protocol}

Data collection was carried out on 3 different days, at the same time of the day, apart from each other by 2 weeks. In each of these days subjects were randomly assigned to drink $250 \mathrm{ml}$ of energy drink (DAY 1), $500 \mathrm{ml}$ of energy drink (DAY 3) or $500 \mathrm{ml}$ of the placebo drink (DAY 2). Placebo drink was similar in appearance, taste and aroma but had no sugar or any of the active ingredients of the energy drinks. The volume of liquid to be ingested was equalized to $500 \mathrm{ml}$ in all experimental days.

Before the ingestion of the different test beverages, rest heart rate (REST) was measured with a Polar heart rate monitor. After that, the randomly selected beverage for that day was ingested and 40 minutes later heart rate were measured again (PRE-CIRCUIT). Then, subjects proceeded to the circuit to evaluate performance.

Immediately after the circuit test, we measured heart rate (POST-CIRCUIT), time to complete the circuit (performance variable), perceived exertion [14], and technical difficulty (adapted from Borg [14]).

The 40-minute interval after the ingestion of the selected test beverage was considered an average time for the active ingredients to reach their peak [15] [16], and therefore to promote the physiological changes expected.

The circuit to evaluate performance was composed of 10 obstacles. They were supposed to be transposed with basic Parkour skills, such as run, jump and climb, in a determined order as fast as possible. These obstacles had the objective to indirectly evaluate the horizontal and vertical jumps; the moving balance (in the balance beam); the ability to climb; and variables such as agility, decision making, focus, and quick thinking, based on the time to complete the proposed circuit.

In order to minimize the effects of learning the circuit arrangement (for us to evaluate only the effects of the energy drink), we changed the circuit order every test day. The circuits were different in order but similar in difficulties, number of obstacles, and basics skills required. Also, we gave the participants 10 minutes to warm up for the circuit each day so they could get to know the circuit arrangement in that day.

\subsection{Data Analysis}

Data were analyzed with SPSS statistical program (Statistical Package for Social Sciences) version 20.0, for Windows. All variables, except heart rate, were analyzed using variance analysis (ANOVA) one way with Tukey's post hoc. Heart rate was analyzed using repeated measures variance analysis. The significance was set to $p$ $<0.05$. Data were expressed as mean \pm standard deviation.

\section{Results}

\subsection{Heart Rate}

In general, heart rate behaved in the same way in all three days, as shown in Figure 1. There was statistical difference between all moments PRE and POST CIRCUIT when compared to REST $(p<0.001)$ and POST-

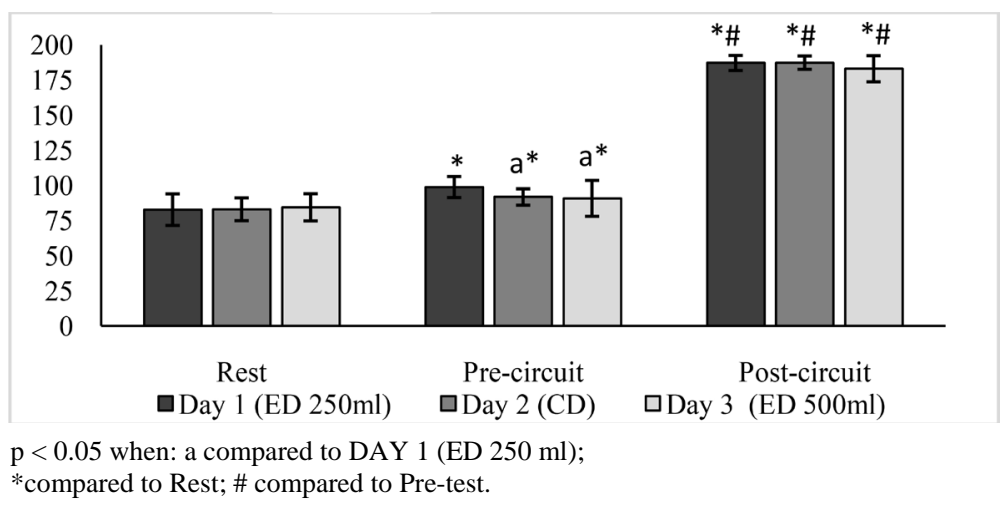

Figure 1. Heart rate at rest, pre and post-circuit in the three different days and beverages. 
CIRCUIT when compared to PRE ( $\mathrm{p}<0.001)$.

The only difference between groups was found at PRE-TEST heart rate. DAY 1 presents significantly higher PRE-TEST heart rate when compared to DAY $2(\mathrm{p}=0.019)$ and DAY $3(\mathrm{p}=0.008)$.

\subsection{Circuit Time}

On DAY 1 (ED $250 \mathrm{ml}$ ) time was significant longer than DAY $2(\mathrm{p}=0.004)$ and DAY $3(\mathrm{p}=0.02)$. However, there was no significant difference between DAY 2 and DAY 3, as presented in Figure 2.

\subsection{Perceived Exertion and Technical Difficulty}

In the same way as circuit time, both the technical difficulty and perceived exertion values were significantly higher on DAY 1 than DAY 2 and DAY3 $(\mathrm{p}<0.001$ ), as shown in Figure 2. Once again, no differences between DAY 2 and DAY3 were found.

\section{Discussion}

\subsection{Heart Rate}

Heart rate presented the same behavior with the consumption of all three beverages, including control drink.

There is controversial evidence about heart rate changes and energy drink consumption, and that promotes several discussions about it. On one side, there are studies as the one published by Ivy et al. [17] that did not found any difference on heart rate after energy drink consumption. On the other side, there are a few authors, like Alford et al. [15], that found significant changes on heart rate after the consumption of only $250 \mathrm{ml}$ of an energy drink.

A recent study published by Siefert et al. [5] observed that heart rate can be increased after the ingestion of energy drinks that had $4 \mathrm{mg} / \mathrm{kg}$ of caffeine. As one can of the energy drink used in our study had $1.12 \mathrm{mg} / \mathrm{kg}$ of caffeine, and two cans had $2.24 \pm 0.24 \mathrm{mg} / \mathrm{kg}$, the absence of difference when we compared REST to PRECIRCUIT might be due to the low caffeine concentration provided. In the present study, the heart rate increase observed in the PRE-CIRCUIT, suggests the effect psychological factors, such as anxiety.

The circuit of obstacles was developed to demand the maximum effort of the participants. Therefore, the heart rate in the POST-CIRCUIT moment was significantly higher compared to the PRE-CIRCUIT and REST in all experimental days due to the exercise demand as expected [5] [17].

\subsection{Circuit Time}

Despite the 10 minutes that were given to the subjects in order to explore the obstacles, the exact sequence was not revealed until the actual test so we could properly evaluate performance. Therefore, we suppose that circuit time were higher on DAY 1 because the subjects were not familiar with the obstacles disposition in the circuit.

Once again, we believe that the main reason the time to complete the circuit were similar between DAY 2 (control drink) and DAY $3(500 \mathrm{ml})$ was the low caffeine concentration that it provides. Although caffeine is considered the main active compound for helping improve performance, and we waited the average time described in the literature for it to be effective, the International Society of Sports Nutrition's (ISSN) published a

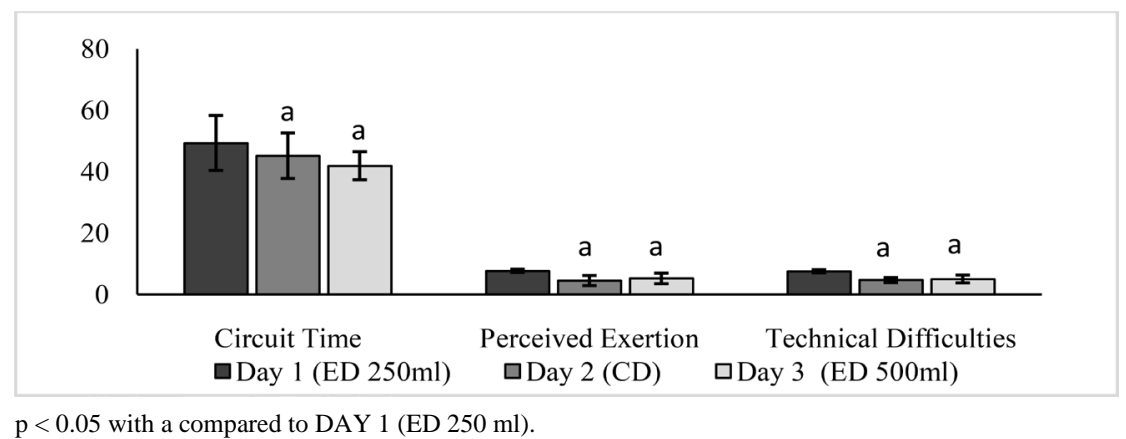

Figure 2. Circuit time, perceived exertion and technical difficulties in the three different days and beverages. 
review [16] report where the minimum effective amount of this substance was around $3 \mathrm{mg} / \mathrm{kg}$. In the present study, as mentioned above one can of $250 \mathrm{ml}$ provided $1.12 \pm 0.12 \mathrm{mg} / \mathrm{kg}$ of caffeine, and two cans provided $2.24 \pm 0.24 \mathrm{mg} / \mathrm{kg}$, which means lower amounts than the minimum pointed out by the literature as effective to improve performance.

There are other studies such as Del Coso et al. [19], Astorino et al. [19], and Forbes et al. [11],which also didn't observed energy drink benefits on performance. The authors showed that one energy drink dose providing $1 \mathrm{mg} / \mathrm{kg}, 1.3 \mathrm{mg} / \mathrm{kg}$ or $2 \mathrm{mg} / \mathrm{kg}$ of caffeine did not improve muscle power, muscle association of strength and speed, sprint time and anaerobic Wingate test in soccer athletes.

Besides, there are only a few studies on the properties of the other compounds present in the energy drinks. Because of that, and because the ergogenic properties of the energy drinks are extremely similar to those promoted by caffeine alone, several researchers believe that the performance results of these drinks are due to caffeine alone [16] [20].

Even with studies as mentioned above, Alford et al. [15] and Ivy et al. [17] observed positive effects with the ingestion of one or two cans of energy drinks on aerobic and anaerobic resistance, focus, alert state and reaction time. This fact raises the hypothesis that other compounds on this beverage (or the association of all of them) might be associated with performance improvement [21] [22].

Seidl et al. [23] found positive effects of taurine in variables such as mood and well-being. However, 1000 mg of taurine present in the energy drink used in this study, acutely, was not enough to improve performance. Rutherford et al. [24] provided almost twice as much (1660 mg) taurine in an energy drink and didn't observe significant differences in time to exhaustion and cardio respiratory fitness. Only when taurine was offered 3 times a day, in a $2000 \mathrm{mg}$ dose, during 7 consecutive days, there was a significant increase in time to exhaustion and work load [9] [25].

As taurine, complex B vitamins are also more effective when they are chronically supplemented [13]. Regarding its acute use, the position stand published by the ISSN [16] says that there are no effects promoted by these substances when used as an ingredient of the energy drinks, because its amounts are much lower than those related to improvements in performance.

\subsection{Perceived Exertion and Technical Difficulty}

As well as in the time circuit, we suppose that both perceived exertion and technical difficulty values were higher on the first day because the subjects were not familiarized with the test.

Since there was no difference in the time to complete the circuit in DAY 2 and DAY 3, and participant's heart rate values were equally higher in the POST-CIRCUIT in the three days, we believe that it was similarly difficult and they only perceived the circuit as less difficult on DAY 2 and DAY 3. This occurred probably due to the learning process involved in the activity, despite all the caution we took to create different circuits, they had to be equivalent in difficulty and number of obstacles. Our results suggest that the experience acquired by the subjects of the circuit on DAY 1 allowed them to associate the proper movements needed to tranpose the obstacles on DAY 2 and DAY 3. With that, they felt their performance on the following experimental days was better, giving the athletes the feeling that physically and technically the circuit was easier [26].

Perceived exertion showed values extremely close to the technical difficulty values. In the last two experimental days the subjects considered the circuit task as being easier both technically and physically, but the heart rate results showed a very high heart rate on all three days, suggesting that the effort was similar every day. We believe that these values reflect the subjects experience in the circuit, because once they knew the obstacles, even in a different arrangement, they considered it easier and simpler [26].

\section{Conclusion}

We concluded that the consumption of one or two cans of an energy drink does not enhance Le parkour performance in a specific short duration and high intensity circuit. This amount was not enough to change heart rate or perceived exertion. More studies are needed to provide a full comprehension of the potential benefits of this type of ergogenic aid.

\section{References}

[1] Leite, N., Junior, P.A., Cieslak, F., et al. (2011) Physical Fitness Profile of le Parkour Practitioners. Revista Brasileira de Medicina do Esporte, 17, 198-201. http://dx.doi.org/10.1590/S1517-86922011000300010 
[2] Guss, N. (2011) Parkour and the Multitude: Politics of a Dangerous Art. French Cultural Studies, 22, 73-85. http://dx.doi.org/10.1177/0957155810386675

[3] Buck, R., Dixon, J., Matjasich, L., et al. (2013) Energy Drink Consumption among Adolescents and Young Adults: Health Effects and Implications for Practice. Master of Science in Nursing, Westminster College School of Nursing and Health Sciences.

[4] Ishak, W.W., Ugochukwu, C., Bagot, K., et al. (2012) Energy Drinks: Psychological Effects and Impact on Well-Being and Quality of Life-A Literature Review. Innovations in Clinical Neuroscience, 9, 25-34.

[5] Seifert, S.M., Schaechter, J.L., Hershorin, E.R., et al. (2011) Health Effects of Energy Drinks on Children, Adolescents, and Young Adults. Pediatrics, 127, 511-528. http://dx.doi.org/10.1542/peds.2009-3592

[6] Burrows, T., Pursey, K., Neve, M., et al. (2013) What Are the Health Implications Associated with the Consumption of Energy Drinks? A Systematic Review. Nutrition Reviews, 71, 135-148. http://dx.doi.org/10.1111/nure.12005

[7] Higgins, J.P., Tuttle, T.D. and Higgins, C.L. (2010) Energy Beverages: Content and Safety. Mayo Clinic Proceedings, 85, 1033-1041. http://dx.doi.org/10.4065/mcp.2010.0381

[8] American College of Sports Medicine, American Dietetic Association, Dietitians of Canada (2009) Nutrition and Athletic Performance: Joint Position Statement. Medicine \& Science in Sports \& Exercise, 32, 2130-2145.

[9] Galloway, S.D., Talanian, J.L., Shoveller, A.K., et al. (2008) Seven Days of Oral Taurine Supplementation Does Not Increase Muscle Taurine Content or Alter Substrate Metabolism during Prolonged Exercise in Humans. Journal of Applied Physiology, 105, 643-651. http://dx.doi.org/10.1152/japplphysiol.90525.2008

[10] Schaffer, S.W., Jong, C.J., Ramila, K.C. and Azuma, J. (2010) Physiological Roles of Taurine in Heart and Muscle. Journal of Biomedical Science, 17, S2. http://dx.doi.org/10.1186/1423-0127-17-S1-S2

[11] Forbes, S.C., Candow, D.G., Little, J.P., et al. (2007) Effect of Red Bull Energy Drink on Repeated Wingate Cycle Performance and Bench-Press Muscle Endurance. International Journal of Sport Nutrition and Exercise Metabolism, 17, 433-444.

[12] Tarnopolsky, M.A. (2010) Caffeine and Creatine Use in Sport. Annals of Nutrition \& Metabolism, 57, 1-8. http://dx.doi.org/10.1159/000322696

[13] Del Coso, J., Muñoz-Fernández, V.E., Muñoz, G., Fernández-Elías, V.E., et al. (2012) Effects of a Caffeine-Containing Energy Drink on Simulated Soccer Performance. PLoS ONE, 7, e31380. http://dx.doi.org/10.1371/journal.pone.0031380

[14] Borg, G. (1998) Borg’s Perceived Exertion and Pain Scales. Human Kinetics, 104 p.

[15] Alford, C., Cox, H. and Wescott, R. (2001) The Effects of Red Bull Energy Drink on Human Performance and Mood. Amino Acids, 21, 139-150. http://dx.doi.org/10.1007/s007260170021

[16] Campbell, B., Wilborn, C., La Bounty, P., et al. (2013) International Society of Sports Nutrition Position Stand: Energy Drinks. Journal of the International Society of Sports Nutrition, 10, 1. http://dx.doi.org/10.1201/b16045

[17] Ivy, J.L., Kammer, L., Ding, Z., et al. (2009) Improved Cycling Time-Trial Performance after Ingestion of a Caffeine Energy Drink. International Journal of Sport Nutrition and Exercise Metabolism, 19, 61-78.

[18] Del Coso, J., Salinero, J.J., González-Millán, C., et al. (2012) Dose Response Effects of a Caffeine-Containing Energy Drink on Muscle Performance: A Repeated Measures Design. Journal of the International Society of Sports Nutrition, 9, . http://dx.doi.org/10.1186/1550-2783-9-21

[19] Astorino, T.A., Matera, A.J., Basinger, J., et al. (2012) Effects of Red Bull Energy Drink on Repeated Sprint Performance in Women Athletes. Amino Acids, 42, 1803-1808. http://dx.doi.org/10.1007/s00726-011-0900-8

[20] Woojae, K. (2003) Debunking the Effects of Taurine in Red Bull Energy Drink. Nutrition Bytes, 9, 1-7.

[21] Wolever, T.M.S. (2003) Carbohydrate and the Regulation of Blood Glucose and Metabolism. Nutrition Reviews, 5, 40-48. http://dx.doi.org/10.1301/nr.2003.may.S40-S48

[22] Batatinha, H.A.P., Costa, C.E., França, E., et al. (2013) Carbohydrate Use and Reduction in Number of Balance Beam Falls: Implications for Mental and Physical Fatigue. Journal of the International Society of Sports Nutrition, 10, 32. http://dx.doi.org/10.1186/1550-2783-10-32

[23] Seidl, R., Peyrl, A., Nicham, R., et al. (2000) A Taurine and Caffeine-Containing Stimulates Cognitive Performance and Well-Being. Amino Acids, 19, 635-642. http://dx.doi.org/10.1007/s007260070013

[24] Rutherford, J.A., Spriet, L.L. and Stellingwerff, T. (2010) The Effect of Acute Taurine Ingestion on Endurance Performance and Metabolism in Well-Trained Cyclists. International Journal of Sport Nutrition and Exercise Metabolism.

[25] Zhang, M., Izumi, I., Kagamimori, S., et al. (2004) Role of Taurine Supplementation to Prevent Exercise-Induced Oxidative Stress in Healthy Young Men. Amino Acids, 26, 203-207. http://dx.doi.org/10.1007/s00726-003-0002-3

[26] Pellegrini, A.M. (2000) A aprendizagem de habilidades motoras I: O que muda com a prática? RevistaPaulista de Educação Física, 3, 29-34. 